Thorax (1970), 25, 643.

\title{
Resorption of calcification in primary pulmonary tuberculosis
}

\author{
J. B. MOR R IS O N \\ Abergele Chest Hospital, North Wales
}

\begin{abstract}
During a long-term follow-up of 10 to 17 years on 383 children aged 2 months to 15 years suffering from primary pulmonary tuberculosis with consolidation-collapse of lung segments, apparent calcification was noted to have disappeared in whole or in part from the lungs and/or lymph nodes of 68 children. This finding was most common in those under 6 years of age on entry to the study, $23.4 \%$ compared with $4.5 \%$ over six years.
\end{abstract}

Thomas (1952) threw doubt on the wisdom of conservative medical treatment for children suffering from primary pulmonary tuberculosis with consolidation-collapse of lung segments. On account of this and because of previous experience of usually successful medical treatment of these lesions, the writer followed up a large series of children having this type of 'epituberculosis' (Eliasberg and Neuland, 1920). All children discharged between 1 January 1952 and 31 December 1959 were followed through the co-operation of their local chest clinics. It had been intended to complete the study in 1965 , but because so many children showed resorption of apparent calcification from the lungs and hilar lymph nodes it was extended to 1968 for those children whose chest radiograph showed calcified lesions. The main study supports the conclusions of other authors, such as Adler and Richards (1953), Bentley, Grzybowski, and Benjamin (1954) and Macpherson, Zorab, and Reid (1960), that this condition should generally be treated conservatively; only $21(5.2 \%)$ of our patients required a thoracotomy.

Two hundred and thirty children were under 6 years of age on entry to the study, 108 were 6 to 12 years and 45 were over 12 years old. Of the series, 338 patients achieved a satisfactory result, 41 were not traced, and 4 died, 2 from unrelated causes and 2 from tuberculous meningitis in the early weeks of treatment. The findings relating to calcium resorption (Table) show that about one-third of those followed with calcified lung lesions or lymph nodes showed partial or complete clearing after 9 to 16 years. To illustrate those findings two case histories are presented.
T A B L E

\begin{tabular}{l|c|c|c|c}
\hline & $1952-59$ & $\begin{array}{c}\mid c \\
\text { Full } \\
\text { Clearing }\end{array}$ & $\begin{array}{c}\text { Partial } \\
\text { Clearing }\end{array}$ & $\%$ \\
\hline $\begin{array}{l}\text { Calcified } \\
\text { lung lesions }\end{array}$ & 122 & 24 & 17 & 34 \\
\hline $\begin{array}{l}\text { Calcified } \\
\text { lymph nodes }\end{array}$ & 84 & 13 & 14 & 32 \\
\hline
\end{tabular}

\section{CASE REPORTS}

CASE 1 D. W. aged 10 months was admitted to Abergele Chest Hospital directly from home on 24 February 1956. She was a contact of a tuberculous father and had an opacity in the right lower lobe

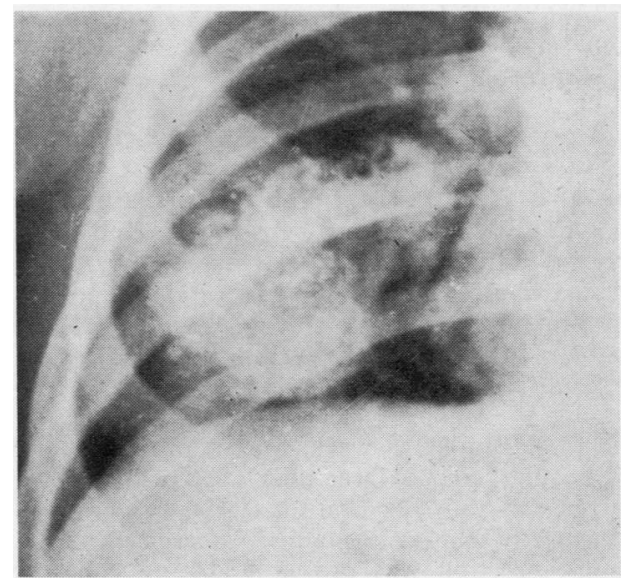

FIG. 1. Case 1. Early calcification in lesion of right lower lobe in 1956. 
which contained many specks of calcification (Fig. 1). The tuberculin skin test was positive by the Heaf Multiple Puncture method and gastric lavage on admission was positive for tubercle bacilli on culture. She was given PAS, $3 \mathrm{~g}$. daily, with INAH, $60 \mathrm{mg}$. daily, from 18 April 1956 to 1 February 1957. From 1 February to 21 August 1957 streptomycin, 500 mg. on alternate days, together with INAH, $60 \mathrm{mg}$. daily, was given in place of PAS because of an apparent increase in the size of the right basal opacity at 11 months from admission, despite a previously contracting lesion as well as six negative gastric lavages on culture. Five weeks after starting streptomycin the right lower lobe shadow was contracting and showed an increase in calcification in two distinct parts. By 1 year and 4 months from onset the right lower lobe shadow showed further clearing and two areas of calcification were quite distinctly separate (Fig. 2). At 1 year and 7 months

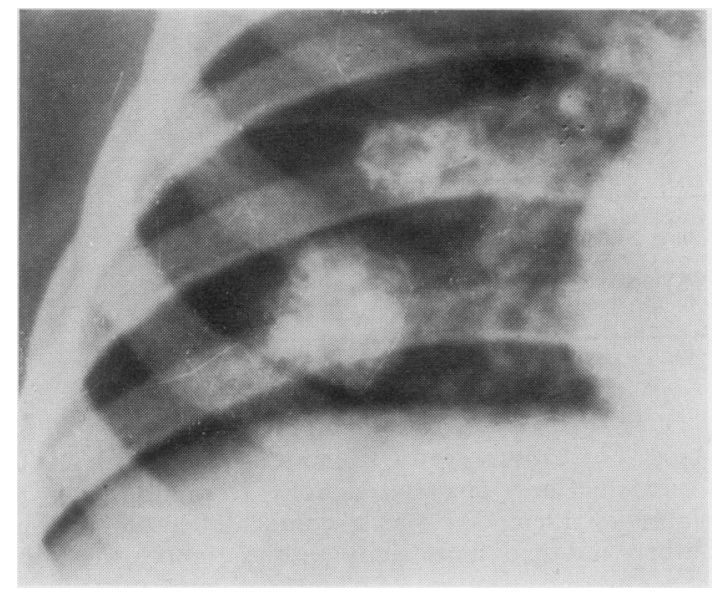

FIG. 2. Case 2. Increased density of calcified areas with clearing between them at 1 year and 4 months from discovery of lesion.

she was discharged well and a chest radiograph taken at 2 years and 3 months showed further clearing of the calcified lesions. By 5 years and 8 months there was only some slight increase in the right basal lung markings and by 9 years and 2 months the chest film showed complete clearing of calcification (Fig. 3). During all this time she had remained symptom-free.

CASE 2 J. P. aged 8 weeks was admitted to a children's hospital on 22 December 1950 with a diagnosis of bronchitis, but his Mantoux test was positive and his gastric washings contained tubercle bacilli. The primary infection was probably due to contact with a tuberculous grandfather within three weeks of birth. His first chest radiograph showed enlarged mediastinal lymph nodes together with an opacity

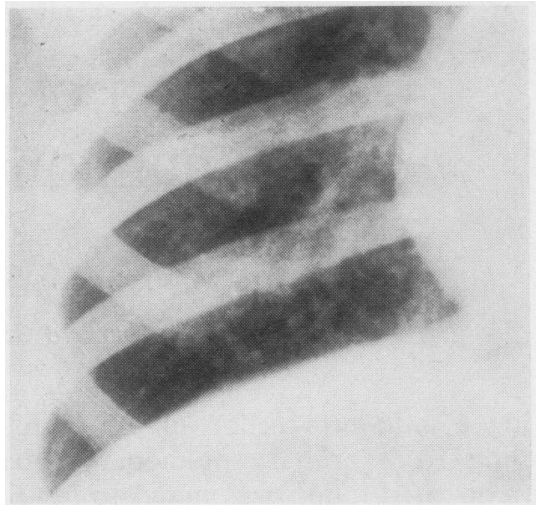

FIG. 3. Case 1. Full clearing of calcification at 9 years and 2 months.

in the left upper lobe involving the apical segment. Without chemotherapy he improved at first but three and a half months after admission he developed measles which was quickly followed by tuberculous meningitis. Streptomycin, $300 \mathrm{mg}$. intramuscularly and $25 \mathrm{mg}$. intrathecally, were both given daily for a period of seven weeks, by which time the cerebrospinal fluid findings had improved and treatment was stopped. He was transferred subsequently to Abergele Chest Hospital on 17 August 1951 and by this time the left upper lobe lesion was contracting and calcifying. Calcification could also be seen in lymph nodes at the root of the neck on the right side (Fig. $4)$. At 2 years and 3 months from onset the left upper lobe lesion had contracted further and showed increased density of calcification and at 2 years and 7 months these changes were much more obvious (Fig. 5). He was discharged well at that time. While on holiday in the area of this hospital 5 years and 7 months from the onset he appeared with his mother, who was anxious to show us how well he had progressed. A further chest film was taken and this showed that the left upper lobe opacity had cleared leaving only slight residual linear streaking back to the root. A small calcified focus was still evident at the root of the neck on the right side. Fourteen years later he appeared at our local chest clinic having left the city of his birth. He was complaining then of a mild bronchitis following on a cold. His chest radiograph taken at this time (Fig. 6) confirmed the clearing of the calcified lesion at the iert apex. This boy has recently been accepted into the Royal Navy.

\section{DISCUSSION}

Calcification may be laid down in tuberculous tissue within months of the primary infection. Brailey (1937) recorded calcification in a 10month-old child who had been exposed to tuber- 


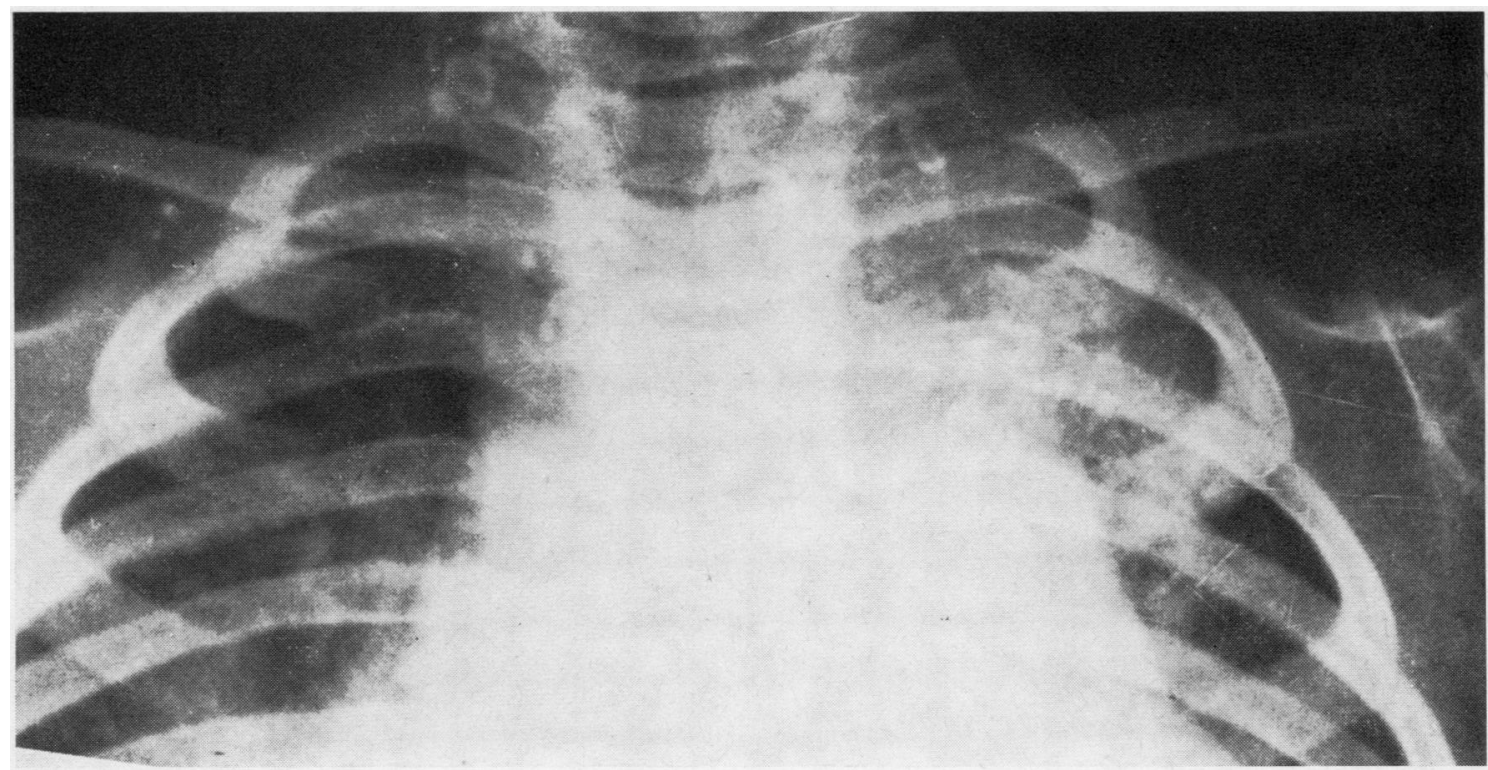

FIG. 4. Case 2. Multiple areas of calcification in left upper lobe and in cervical and mediastinal glands at 1 year and 8 months from onset in 1950.

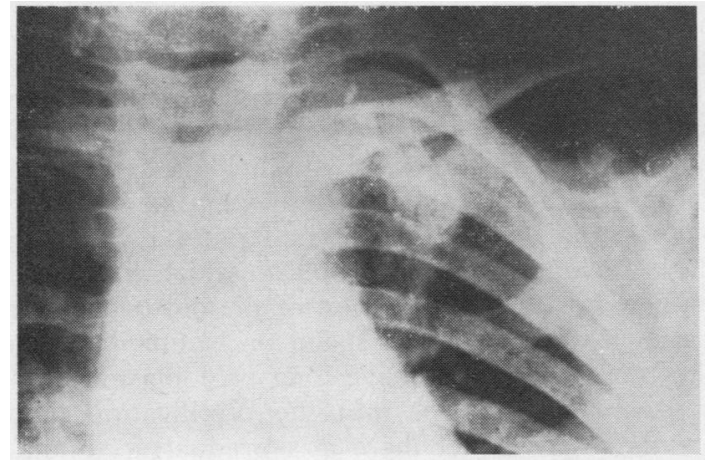

FIG. 5. Case 2. Partial clearing of left upper lobe consolidation and increased density of calcification within it at 2 years and 7 months from onset.

culous infection for the first month of life and who had a positive tuberculin test at the age of 6 weeks. In a study of 158 children, she mentions that in $90 \%$ of the cases calcification first appeared in the tracheobronchial lymph nodes. Associated calcifying pulmonary nodules were observed simultaneously in about one-third of those cases and in another one-third pulmonary nodules appeared later. Calcification appeared in the chest in about $17 \%$ of children observed one year after the discovery of tuberculous infection and this proportion rose to $47 \%$ at the end of two years, to $62 \%$ by the end of three years, and to $66 \%$ at the end of four years. Macpherson (1957) records calcification as having been observed in a child of 8 months attending the Brompton Hospital Children's Contact Clinic. One of our children showed quite definite calcification at six to eight months from onset.

Little is recorded in the literature on resorption of calcified foci from lungs or lymph nodes and the generally accepted view is to assume that the calcified areas are coughed out. Brailey (1937) records the disappearance of a calcified lesion from the lung of a child who was 26 months old when the nodule was first recorded. It contracted over a period of years and had disappeared by the fourth year from its discovery. This, however, was in only one patient out of a series of 158 children aged under 2 years at the time of infection. I have often noticed in the early stages of calcification that there is a granular appearance: this, too, is recorded by Brailey. Some of these early lesions had an eggshell appearance with more loosely packed calcified granules beneath the outer rim: such an eggshell calcification is a well-known appearance in the hilar nodes of the North Wales slate quarry worker. Broncholiths, which are coughed out in older children and adults, are usually accompanied by definite 


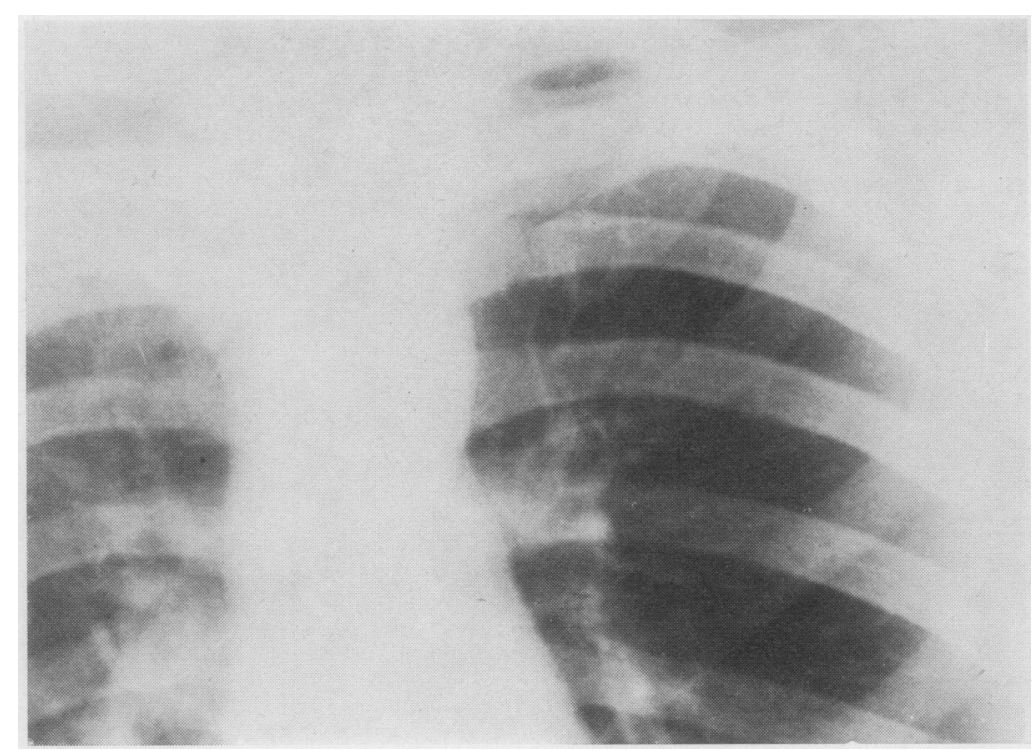

FIG. 6. Case 2. Full clearing of calcified left upper lobe lesions at 14 years from onset in 1964.

symptoms which may include haemoptysis, but none of our patients had any symptoms whatsoever.

A careful study of the radiographs over months and years shows that calcium resorption is usually a gradual process and is associated with shrinking of the lesions, though it is important to be sure that the calcified hilar nodes have not become hidden behind the sternum as they shrink. The remarkable clearing of calcification illustrated in the two patients above, and in many others of the series, suggests that some process other than simple expectoration of calcified masses is at work and that calcified lesions can frequently be resorbed. In his description of the age morphology of primary tubercles, Sweany (1941) states that 'calcification shows first at about five months in sections stained with Haemalum and Eosin and around one year in post-mortem $x$-rays. It increases for about 10 years and then is gradually resorbed or changed to bone. Around five years resorption occurs between the calcified core and capsule of the tubercle-leaving open spaces in which capillaries form. This process continues until nearly all calcification and fibrous capsule are resorbed. Bony changes are present in $85 \%$ of tubercles after ten years. In the other $15 \%$ there is fragmentation of the calcification by fibrous tissue, hyalinization of the calcification and fibrous tissue and other changes that indicate advanced age.' It may well be that drug treatment shortens this cycle. Sweany states that the cells responsible for this process appear to come from the basic reticulum itself, others seem to be a transition from old fibrocytes, while others may be histiocytes which have migrated into the area from the body fluids. These cells have many shapes, one being like a small plasma cell with dark nucleus and pink cytoplasm which can digest its way into the calcification of the old connective tissue leaving an open space or lacuna between the two. Other cells have long protoplasmic processes which project into the calcification, and around their nuclei there is a gradual accumulation of collagen which extends into the calcification and gradually changes into bone. Another type of cell resembles the basic reticulum cell but later forms cells which resemble fibroblasts; these cells are accompanied by capillaries and can also cause resorption. The existence of these peculiar cells was not known to the writer when he first noted the disappearance of calcification from the left upper lobe of case 2 (Fig. 7).

Apart from histological considerations the reason why calcification is laid down and in some patients increases while in others it is resorbed is unknown. In fact in the same patient calcification has been noted to be resorbing at one site while being laid down at others. In order to try to explain the chemistry of the process several authorities on calcium 


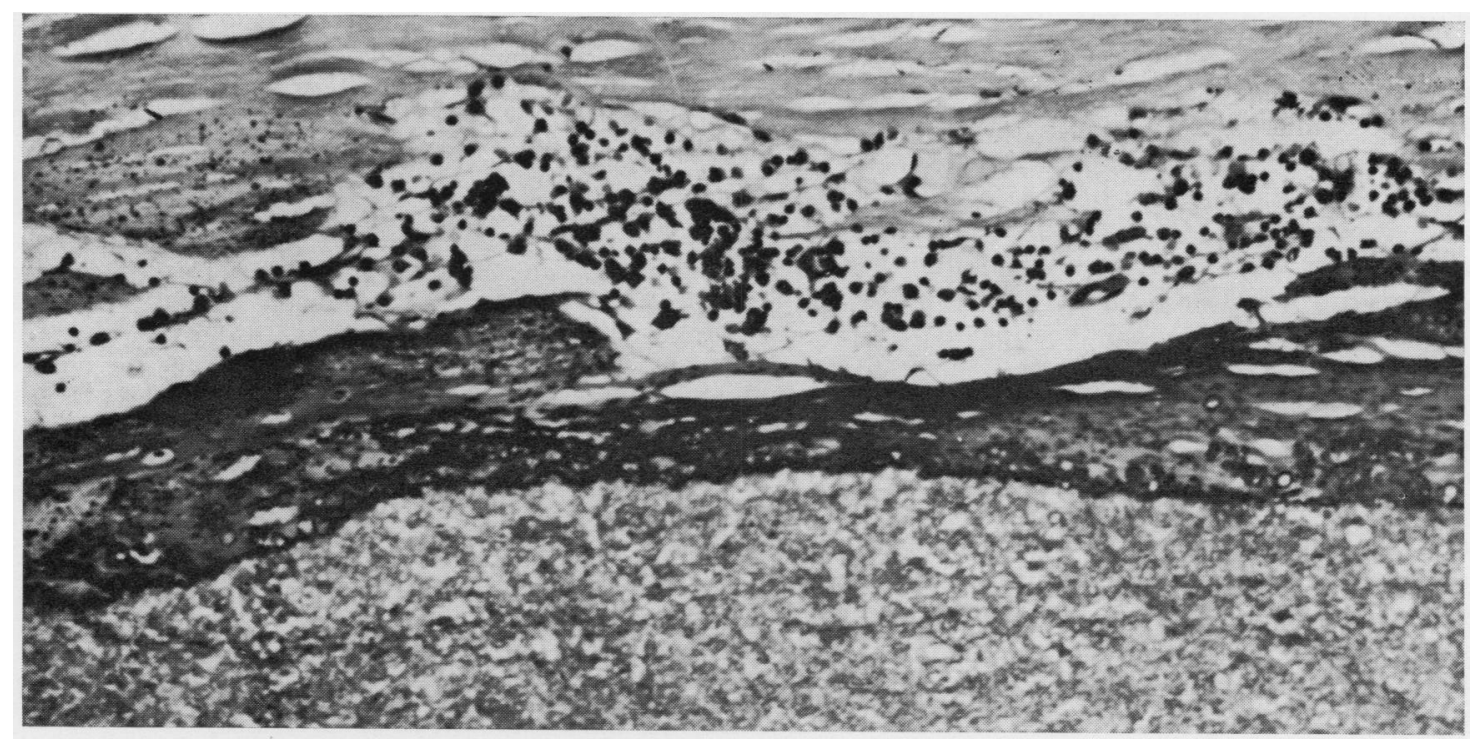

FIG. 7. Shows a tubercle with a zone of resorption of calcification between the caseous core and fibrous capsule which is also in part being resorbed. The monocytic cells involved in the process are clearly seen. $H$. and E. $\times 170$.

metabolism have been consulted. Dent (1965), in a personal communication, comments that 'other sorts of calcification usually follow the general rule that if they are deposited quickly and the cause is quickly removed they may disappear. The more slowly they are deposited and the longer it is before the disease process is reversed, the less likely it is for them to be removed. I have in mind calcification due to ingestion of too much milk, overdose of vitamin $\mathrm{D}$, primary hyperparathyroidism, and secondary calcification following tissue damage such as dermatomyositis. I think the latter must be similar to the process you are observing in your children.' No doubt the monocytic cells described by Sweany (1966) are the mediators of it. As to the actual chemical composition of the deposits, Nordin (1969), also in a personal communication, states that the exact composition of these calcific deposits is not known. One must assume that they are deposits of calcium phosphate which at the $p \mathrm{H}$ of plasma will take the form of apatite. Assuming then that it is apatite, the first question is why calcification occurs and the second is why and how do the deposits dissolve. As far as the first question is concerned, the extracellular fluid is supersaturated with respect to calcium phosphate which will tend to precipitate out on an appropriate nucleus. One imagines that the normal soft tissues do not have this nucleating property or are protected by some kind of inhibitor from calcification and that abnormal, degenerate, fibrotic tissue acts as a nucleus or alternatively lacks the appropriate inhibitor whatever that may be. As far as the second question is concerned, it is difficult to understand how the deposits can dissolve in the presence of supersaturated fluids unless the high $\mathrm{PCO}_{2}$ prevailing in pulmonary tissue alters the $p \mathrm{H}$ sufficiently to cause local undersaturation. If, however, this is the mechanism why did the deposits form in the first place? One relevant point might be the difference in serum phosphorus level in adults and children. Could it be that there is sufficient supersaturation to form the deposits from child plasma but when the plasma phosphorus falls with age undersaturation and dissolution occurs?' Lorber (1966) has also described the clearing of miliary calcification from the lungs of children. Among 32 children who had miliary tuberculosis between 1947 and 1959 late chest radiographs were available for 1965 or 1966 in 24 and of these there were 15 with no detectable lesions in the lungs. However, several of these patients had had calcified foci earlier in the course of their disease, and in one child the miliary shadows disappeared to reappear later in the calcified form, only to disappear once more completely. There were no symptoms related to these radiological events in any of the children. Sweany (1966), in a personal com- 
munication, remarked that 'the calcification of histoplasmosis is denser and that he had not seen erosion of chalky lesions of this type as in the lungs of tuberculous children'.

I suggest that a commonly held view that calcification is indicative of firm healing does not apply so far as the lungs and mediastinal lymph nodes of young tuberculous children are concerned, but merely reflects a stage in the dynamic process leading to final healing or resolution which might be hastened by chemotherapy. Whether calcification will persist or disappear it is not possible to foretell. If the exact mechanism of calcification and of its disappearance could be elucidated it might be useful in dealing with undesirable calcification such as occurs in muscle tissue after injury or on damaged heart valves or on replacement cadaver valves. Berlyne (1968) states in relation to conjunctival calcification that the common factor in this phenomenon is the high plasma inorganic phosphate with a low or normal plasma calcium. At the limbus there are two boundary zones in close contact where factors combine to produce a higher $p \mathbf{H}$ locally. Calcium salts deposit more strikingly at the limbus than elsewhere in the eye. Perhaps the $p \mathrm{H}$ of caseous tuberculous tissue is such that it predisposes to calcification, especially in young children who have higher serum phosphorus levels as phosphate than do adults. With ageing the $p \mathrm{H}$ may alter sufficiently to encourage resorption of calcification by the monocytic cells. Whatever the mechanism it is a phenomenon which occurs much more often than has generally been accepted in the past, especially in young children.
Grateful acknowledgment is made to the staff of the Manchester Chest Clinic and in particular to Dr. W. L. Anderson and Mr. L. Hinckley for providing the follow-up case notes and radiographs; also to the staff of other chest clinics in Lancashire, Cheshire, and North Wales who helped similarly. My thanks are due to Dr. A. R. Morrison, Dr. W. Lesh, and Dr. G. Lewis for assistance in abstracting case notes. I wish to thank Mr. Ivor Lewis who carried out the surgery on children requiring it, and Mr. F. R. Edwards for help with this text. I am also most indebted to Dr. R. M. E. Seal of Sully Hospital for the photomicrograph, and to Miss M. Wilson, Miss A. Davies and Mrs. J. M. Williams for help with much secretarial work involved. The work was supported by a grant from the Welsh Hospital Board and I wish to thank the research committee for this.

\section{REFERENCES}

Adler, D., and Richards, W. F. (1953). Consolidation in primary pulmonary tuberculosis. Thorax, 8, 223 .

Bentley, F. J., Grzybowski, S., and Benjamin, B. (1954). Tuberculosis in Childhood and Adolescence, pp. 27-49. National Association for the Prevention of Tuberculosis, London.

Berlyne, G. M. (1968). Microcrystalline conjunctival calcification in renal failure. Lancet, $2,366$.

Brailey, M. (1937). Observations on the development of intrathoracic calcification in tuberculin positive infants. Bull. Johns Hopk. Hosp., 61, 258.

Dent, C. E. (1965). Personal communication.

Eliasberg, H., and Neuland, W. (1920). Die epituberkulöse Infiltration der Lunge bei tuberkulösen Säuglingen und Kindern. Jb. Kinderheilk., 93, 88.

Lorber, J. (1966). The long-term prognosis of generalised miliary tuberculosis in children. Lancet, $2,1447$.

Macpherson, A. M. C. (1957). In Symposium of Tuberculosis, ed. Heaf, F. R. G., p. 598, Cassell, London.

Zorab, P. A., and Reid, Lynne (1960). Collapse of the lung associated with primary tuberculosis: a review of 51 cases. Thorax, 15, 346.

Nordin, B. E. C. (1969). Personal communication.

Sweany, H. C. (1941). Age Morphology of Primary Tubercles, p. 91. Thomas, Springfield, Illinois.

- (1966). Personal communication.

Thomas, D. (1952). Contribution to "Discussion on the fate of the tuberculous primary complex". Proc. roy. Soc. Med., 45, 743. 